\title{
Corrosion's impact on wire rope strand response - Comparison with a theoretical predictive model
}

\author{
Amal Tijani \\ Laboratory of Atmosphere's Physics, materials and modeling, FST Mohammedia, Hassan II University of Casablanca, BP 146 - \\ Mohammedia, Morocco \\ amaltijani@gmail.com, bttp://orcid.org/0000-0003-4543-1253
}

\section{Meryam Meknassi}

Laboratory of Control and Mechanical Characterization of Materials and Structures, National Higher School of Electricity and Mechanics (ENSEM), Hassan II University of Casablanca, B.P 8118 Oasis - Casablanca, Morocco

\section{Hassan Chaffoui}

Laboratory of Atmosphere's Physics, materials and modeling, FST Mohammedia, Hassan II University of Casablanca, BP 146 Mohammedia, Morocco

Mohamed Elghorba

Laboratory of Control and Mechanical Characterization of Materials and Structures, National Higher School of Electricity and Mechanics (ENSEM), Hassan II University of Casablanca,

B.P 8118 Oasis - Casablanca, Morocco

\begin{abstract}
In this work, we investigate the behavior of wire ropes when they are subject to corrosion damage. The method is based on accelerated corrosion using experimentation as well as a theoretical predictive model. The experimental approach used static tensile tests on corroded strands. A loss in rigidity and decrease of the ultimate force was observed. For the predictive model, the residual ultimate force was evaluated at a time $t$ in function of the initial diameter, the residual diameter at time $t$ and the ultimate force of the original strand. Given that the obtained residual force evolution depending on the strand's fraction of life matched for both methods, the proposed predictive model can be used by engineers to assess if the wire rope needs to be changed to ensure a good maintainability of structures. Actually, when the applied force on the wire rope approaches its residual bearing force determined by a measure of the residual diameter, the wire rope removal is mandatory.
\end{abstract}

KEYWORDS Wire rope; Accelerated corrosion; Damage; Residual force; Reliability; Predictive maintenance.

\section{OPEN ACCESS}

Citation: Tijani, A., Meknassi, M., Chaffoui, H., Elghorba, M., Effect of corrosion on wire rope strand response - Comparison with a theoretical predictive model, Frattura ed Integrità Strutturale, 50 (2019) 141-148.

Received: 24.05 .2019

Accepted: 19.07.2019 Published: 01.10.2019

Copyright: (C) 2019 This is an open access article under the terms of the CC-BY 4.0, which permits unrestricted use, distribution, and reproduction in any medium, provided the original author and source are credited. 


\section{INTRODUCTION}

A lot of civil engineering structures use wire ropes [1] like suspended bridges, cable stayed bridges, prestressed concrete structures or cableways. Being involved in the structure of a large part of road and rail networks, these elements are subject to mechanical, thermal and environmental solicitations. Thus, regular monitoring and maintenance are mandatory in order to avoid any consequent economic and social disagreement due to the closure of the supported structure. The main function of a wire rope in an engineering structure is to transmit the traction load from the deck to the piles (suspended and cable stayed bridges) or to compress the concrete (prestressed structures). According to their use, wire ropes are exposed to variable loading levels in more or less aggressive environment.

These cables are made of drawn steel wires which have a very high tensile strength and a carbon content close to the eutectoid [2]. Wire drawing is a process of wire transformation which consists in hardening the machine wire and then improving their mechanical characteristics by reducing their diameters when passing through dies. Thus, wire ropes have high yield strength and can support high axial loads. Thanks to their multi-component nature, the cable can continue to ensure its function in spite of the breakage of one or more wires. Indeed, in a multi-stranded cable, a broken wire has the ability to re-anchor by friction and to recover its load capacity [3]. Moreover, their flexibility makes it possible to store them on coils, which facilitates their implementation on structures, but also promotes their use in lifting gear thanks to the possibility of passage through pulleys.

During their service life, broken wires appear on the wire ropes. In that respect, most codes and regulations use the number of broken wires as a criterion for quantifying the degradation level [4]. Moreover, regarding the low alloy steel composition and the environmental conditions (marine atmosphere, pollution, rain, etc.), the cables have an "ordinary" predisposition to corrosion [5]. So far, it is still difficult to quantify the impact of corrosion on the state of the structure and its safety of use.

Drawn steel corrosion has been investigated in conditions simulating the wire rope loading in prestressed concrete structures (stress corrosion) [6] and in bridges (fretting-fatigue corrosion) [7]. The Fatigue strength reduction due to corrosion was studied in the case of bolted joins using an accelerated process of the marine-industrial environment [8]. Fretting fatigue of wire ropes used in coal mines has been studied in four different corrosive medias [9]. This work was carried out at the scale of the wire.

Other research focused on the breakage of wires in wire ropes and their impact on the cable behavior. Beltrán and De Vico used numerical modeling for the study of wire ropes behavior with asymmetric damage [10,11].Wang et $\mathrm{Al}$ [12] investigated the wire failure mechanisms by acoustic emission, Torkar and Arzensi [13] investigated the failure of a crane wire rope. The main reasons were fatigue and lack of inspection.

This work is a contribution to the methods of predicting the wire ropes behavior and life time. The influence of corrosion is investigated at the strand's scale. The choice of carrying out our study on the strand's scale is justified by the following points:

- The strand is representative of the wire rope. This is, in fact, a specific case of wire rope construction (strand wire). The results obtained for a strand can therefore be extended to the case of the cable;

- Taking into account the evolution by layers of the corrosion [14], it is necessary to have data not only on the corrosion of the constitutive wires but also on that of the strands.

The proposed method is based on accelerated corrosion by immersing strands in sulfuric acid for different lengths of time. Besides, damage estimation is obtained by only static tensile tests.

\section{MATERIAL AND METHODS}

1

he wire rope used for this research is manufactured by Bridon, of type $19 * 7(1 * 7+6 * 7+12 * 7)$, rotation resistant, $10 \mathrm{~mm}$ diameter, with independent wire rope core (IWRC), right hand lay and preformed. General characteristics of the cable are given on table 1.

\section{Specimens preparation}

Samples are prepared in accordance with the ISO standard 6892 [15] relative to tensile tests on metal materials. Strands are extracted from the external layer of the wire rope cut beforehand to a length of $300 \mathrm{~mm}(200 \mathrm{~mm}$ according to the ISO standard over $100 \mathrm{~mm}$ required for mooring). This operation is carried out with particular care so as not to damage the specimens. Then, in the same way, wires are extracted from the strands. 


\begin{tabular}{ll}
\hline Cable diameter & $10 \mathrm{~mm}$ \\
Construction & $19 \mathrm{x} 7$ \\
Strand diameter of external layer & $1.9 \mathrm{~mm}$ \\
Strand diameter of internal layer & $2.1 \mathrm{~mm}$ \\
Wire rope core diameter & $2.4 \mathrm{~mm}$ \\
Strand wire diameter & $0.58 \mathrm{~mm}$ \\
Strand core diameter & $0.68 \mathrm{~mm}$ \\
Strand construction & $6 / 1$ \\
Coating & galvanized \\
Core & Metallic \\
Approximate mass & $40.4 \mathrm{~kg} / 100 \mathrm{~m}$ \\
Lubrication & A2/W-3 \\
Breaking force & $68.6 \mathrm{KN}$ \\
\hline
\end{tabular}

Table 1. Wire rope general information

\section{Corrosive solution}

The objective of studying the behavior of corroded wire ropes is reminded in the ISO standard 7539 [16]: 'The objective of corrosion tests is, in general, to provide information faster than this obtained from experience in service and in the same time, to predict the behavior in service". Every kind of material has a susceptibility to corrosion in a specific media. In our case, we have the choice between the solutions below:

- Solution $\mathrm{NaOH}$

- Nitrate solution

- Carbonate solution

- Sea water

- $\mathrm{H}_{2} \mathrm{~S}$

In their paper, Wang et $\mathrm{Al}$ [17] studied the corrosion fatigue phenomena under 4 different medias : hydrochloric acid, sulfuric acid, water sea and neutral solution. The research demonstrated the influence of the sulfuric acid on the drawn wires. It was the media which reduces the most the life time of the material. For this purpose, we choose to use a corrosive solution based on sulfuric acid.

Furthermore, in a precedent research aimed in the determination of the critical acid concentration, Meknassi et Al [18] experimented the corrosion of drawn wires from a 19x7 wire rope in solutions of different concentration of sulfuric acid (from $10 \%$ to $90 \%$ with a step of $10 \%$ ). The critical concentration was found for $30 \%$ of sulfuric acid.

\section{Strands and wires chemical damage}

In order to damage the central part of the strands and wires, the specimens are immerged in the acid solution according to the scheme in figure 1. The depth of the solution is fixed such as we obtain a corroded length of $100 \mathrm{~mm}$ for each sample. The immersion time is: $4 \mathrm{~h}, 8 \mathrm{~h}, 16 \mathrm{~h}, 24 \mathrm{~h}$ and $32 \mathrm{~h}$.

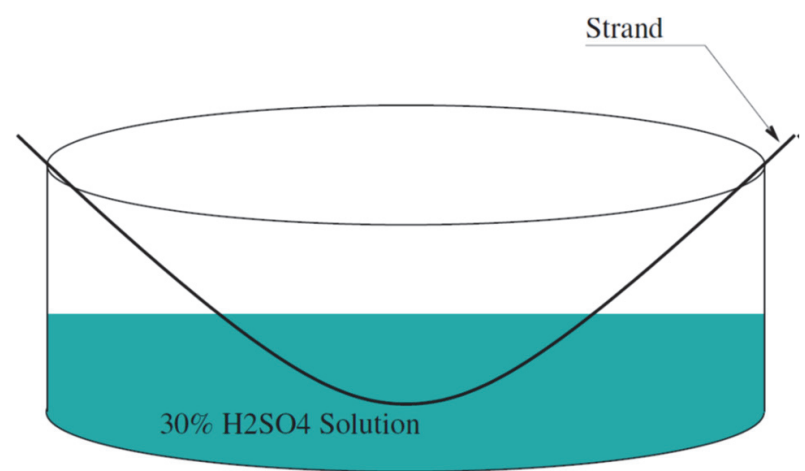

Figure 1. Accelerated corrosion procedure 


\section{Tensile tests}

Tensile tests are made under imposed displacement corresponding to a speed of $1.5 \mathrm{~mm} / \mathrm{min}$ [19] on a Zwick Roell machine with a loading capacity of $\pm 10 \mathrm{KN}$. Photos of the testing machine and a strand specimen after tensile test are represented on figure 2 .

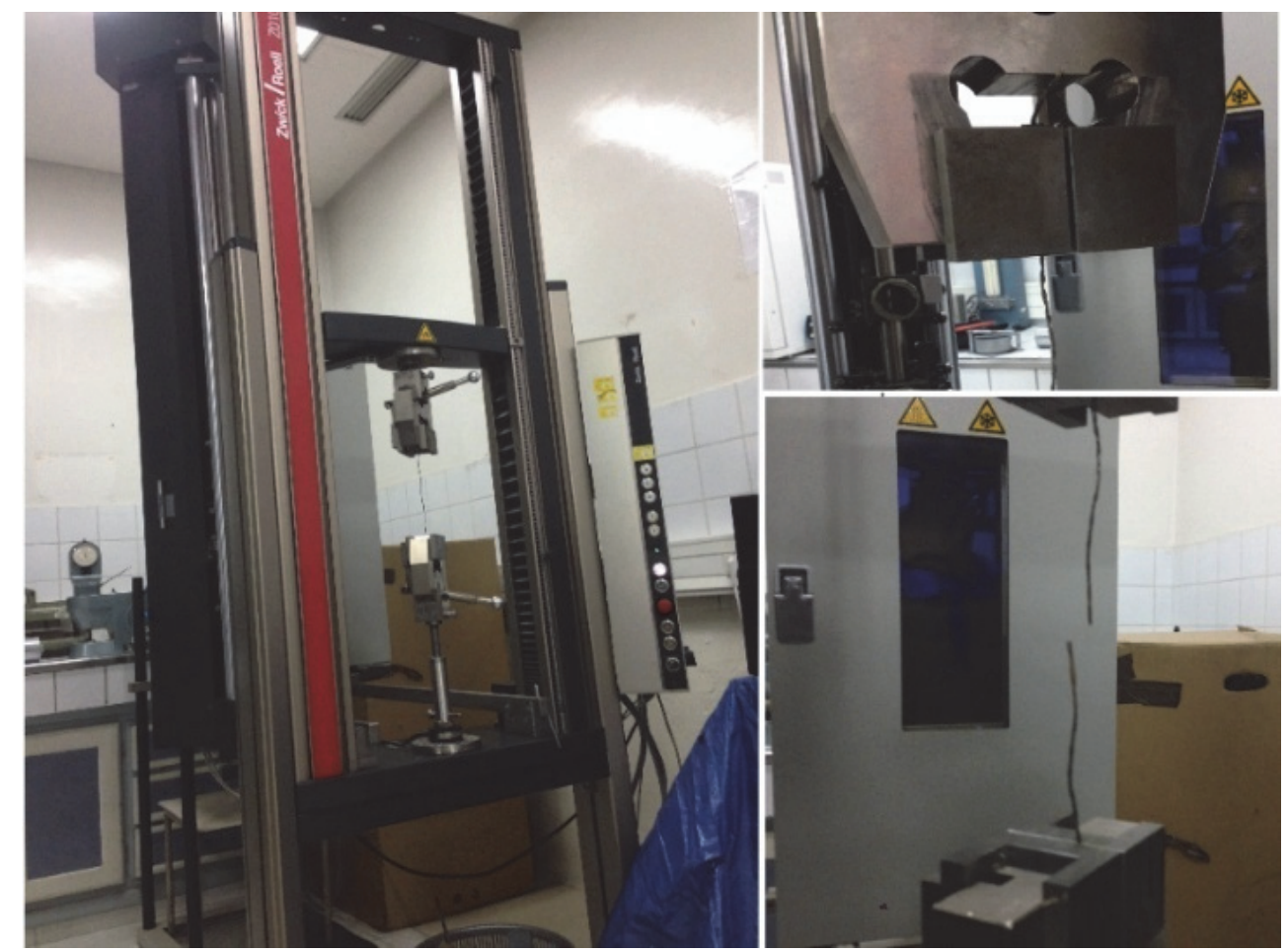

Figure 2. Fitting of test specimens on the testing machine - Zoom on the fixing jaws - Overview of a strand after the tensile test

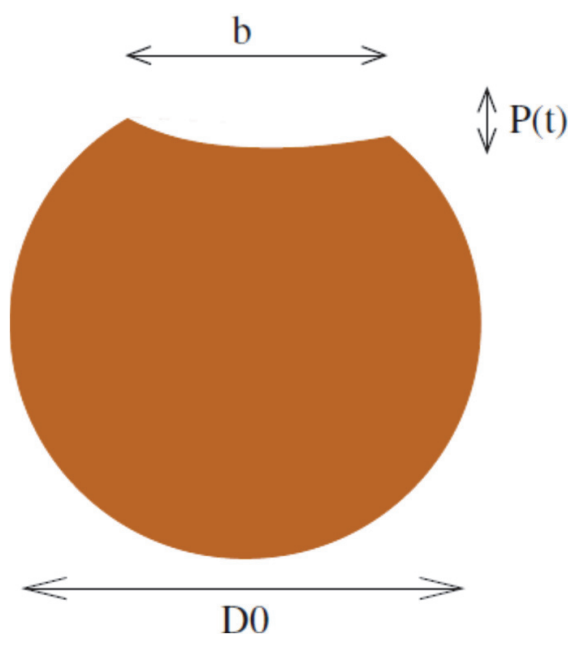

Figure 3. Wire's pit configuration

\section{CORROSION STRENGTH CALCULATION}

$\mathrm{I}$

$\mathrm{n}$ this section, we propose to estimate the strands loss of strength after their corrosion in function of the fraction of lifetime. To do so, we will estimate the loss of strength according to the Stewart model [20] based on the loss of corroded section. 


\section{Corroded section calculation}

According to $\mathrm{Val}$ et $\mathrm{Al}$ [21], the section consumed by corrosion $A_{p}(t)$ is expressed in formula 1. It uses a probabilistic analysis of experimental data to determine the maximum corrosion depth $\mathrm{p}(\mathrm{t})$ and the geometrical shape of the corroded wire section.

$$
A_{p}(t)=\left\{\begin{array}{lll}
A_{1}+A_{2} & \text { if } \quad P(t) \leq \frac{D_{0}}{\sqrt{2}} \\
\pi \frac{D_{0}^{2}}{4}-A_{1}+A_{2} & \text { if } & \frac{D_{0}}{\sqrt{2}}<P(t) \leq D_{0} \\
\pi \frac{D_{0}^{2}}{4} & \text { if } & P(t)>D_{0}
\end{array}\right.
$$

With:

$$
\begin{aligned}
& A_{1}=0.5\left[\theta_{1}\left(\frac{D_{0}}{2}\right)^{2}-b\left|\frac{D_{0}}{2}-\frac{P(t)^{2}}{D_{0}}\right|\right] \\
& A_{2}=0.5\left[\theta_{2} P(t)^{2}-b \frac{P(t)^{2}}{D_{0}}\right] \\
& b=2 P(t) \sqrt{1-\left(\frac{P(t)}{D_{0}}\right)^{2}} \\
& \theta_{1}=2 \arcsin \left(\frac{b}{D_{0}}\right) \\
& \theta_{2}=2 \arcsin \left(\frac{b}{2 P(t)}\right)
\end{aligned}
$$

The residual surface of the wire is then:

$$
A_{a}(t)=\frac{\pi D_{0}^{2}}{4}-A_{p}(t)
$$

Tensile strength reduction of the corroded wires

Structures are designed to withstand permissible loads. When attacked by corrosion, the decrease of wires's cross-section induces a reduction in their strength. Thus, irreversible damage can occur leading to the collapse of the structure. It is therefore important to take into account the reduction of the resistance of the corroded elements if it is desired to keep them in service. The model described by Stewart et al. [20] expresses the strength of the corroded wires $f_{\text {py }}(t)$ as a function of the strength of the undamaged wires $\mathrm{f}_{\mathrm{py} 0}$ :

$$
f_{p y}(t)=\left(1-\alpha_{y} \frac{A_{p}(t)}{A_{a}(t)}\right) f_{p y 0}
$$


where $\alpha_{\mathrm{y}}$ is a coefficient of a mean value to consider equal to 0,005 .

\section{RESULTS AND DISCUSSION}

\section{Predictive force loss}

he multi-component nature of the strand does not allow us to clearly measure the section of the corroded samples. To this end, wire samples extracted from the cable subject to this study were subjected to corrosion under the same conditions as the strands. The diameter loss ratio was recorded for different lifetimes [18].

\begin{tabular}{llllllll}
\hline Corrosion time (in hours) & 0 & 4 & 8 & 16 & 24 & 32 & 40 \\
Diameter loss ratio (in \%) & 0 & 7 & 15 & 25 & 35 & 50 & 80
\end{tabular}

Table 2. Diameter loss ratio in function of the immersion time in the corrosive solution

Instead of using the probabilistic model of the consumed section by corrosion $A_{p}(t)$ which can change in function of the material [20], we change the formula (3) and express it in function of the residual diameter, the ultimate and residual force of the wire. Thus, the experimental data relative to our wire will be used. The expression becomes:

$$
F_{u r}=\left[D_{r}^{2}-\alpha_{y}\left(1-D_{r}^{2}\right)\right] F_{u}
$$

Where:

$F_{u r}$ is the residual force of the corroded wire;

$F_{u}$ is the ultimate force of the undamaged wire;

$D_{r}$ is the residual diameter ratio; it represents the balance of the diameter loss ratio.

\section{Experimental strands force loss}

The resulting tensile tests on the corroded strands are represented on figure 4. The mean residual tensile forces obtained for each immersion time are illustrated on table 3. In addition to the reduction of the residual force which increases with the acid immersion time, a decrease in the rigidity of the strands is observed. This has also been noted in other studies[22][23].

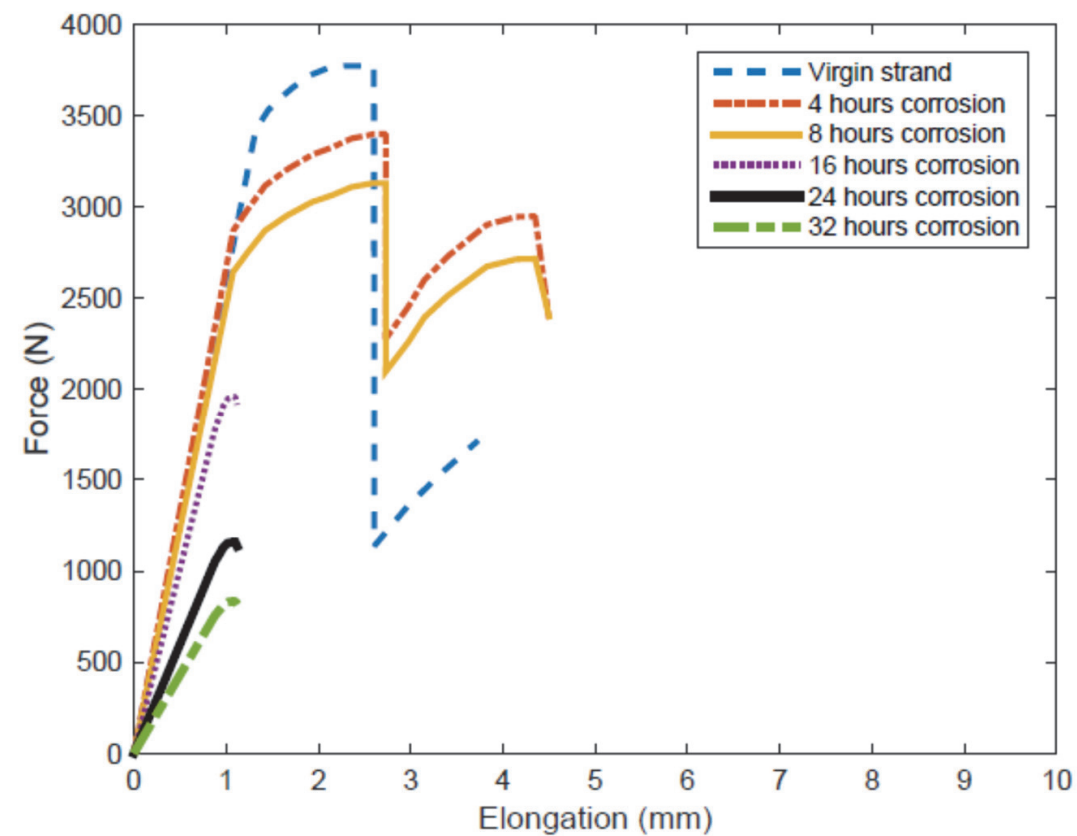

Figure 4. Representative tensile curves of the corroded strands 


\begin{tabular}{lcccccc}
\hline Immersion time (in hours) & 0 & 4 & 8 & 16 & 24 & 32 \\
Residual ultimate force (in N) & 3770 & 3397 & 3130 & 1960 & 1160 & 834 \\
\hline
\end{tabular}

Table 3. Residual ultimate forces of corroded strands for different immersion times

Thus, we draw the theoretical and experimental curves of the ultimate force reduction rate as a function of the life fraction (Fig. 5). The ultimate force reduction rate is equal to the ratio between the ultimate residual force of the corroded material at time $t$ and the ultimate strength of the original material. The fraction of life corresponds to the ratio between the time $\mathrm{t}$ in hours and the total time corresponding to the loss of total resistance of the material which was set to $40 \mathrm{~h}$.

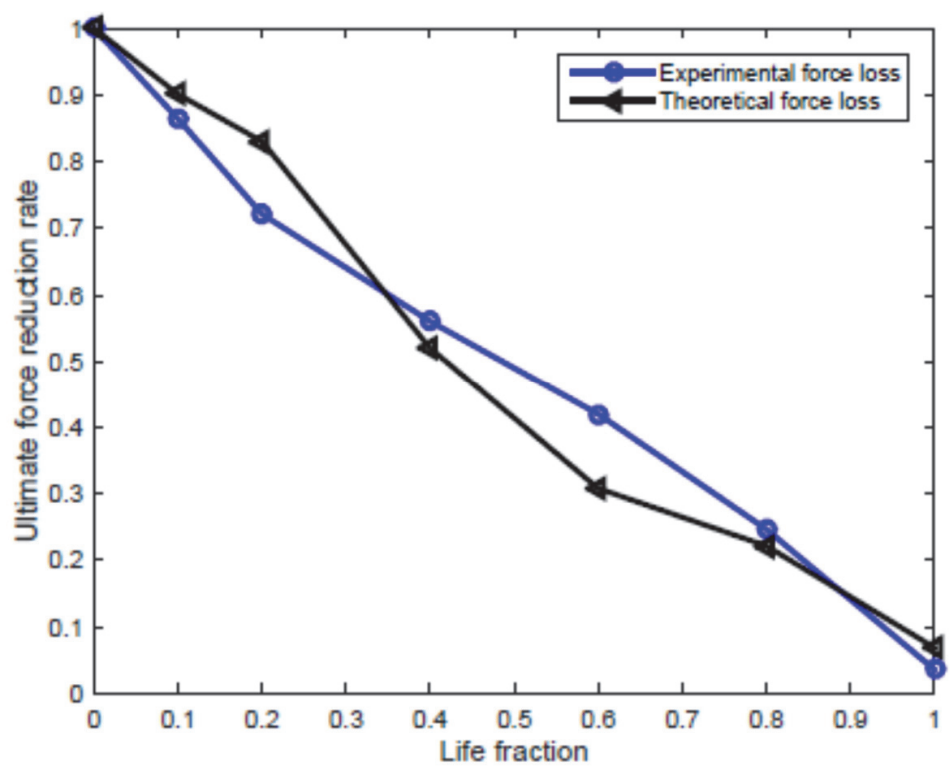

Figure 5. Ultimate force reduction rate in function of the life fraction of the strands - Loss of experimental and theoretical force

From the figure, we can see that the curves obtained experimentally and deduced theoretically correspond overall. Thus, the correspondence between the wire's scale and the strand's scale can be established.

\section{CONCLUSION}

$\mathrm{I}$ $\mathrm{n}$ this paper, we were interested in evaluating the impact of corrosion on the wire rope behavior. The choice of the corrosive solution was based on the material sensibility and preliminary tests aimed to set the critical acid concentration. Static tensile tests were made on the virgin and corroded strands. The high resistance of the material was confirmed.

The ultimate strength was up to $1935 \mathrm{MPa}$ with yield strength of $1800 \mathrm{MPa}$. As a fact, the drawn wires work essentially on elastic phase. Tensile tests on the corroded strands showed a decreasing ultimate force with the increasing corrosion time. A loss in strand's rigidity was also observed in the corroded strands.

Besides, theoretical formulation was developed to predict the corrosion influence on the wire ropes strength. The formulation gives the residual ultimate force estimation at time $t$ in function of the initial diameter, the residual diameter at time $t$ and the ultimate force of the original strand (before corrosive damage).

A monitoring at the wire's scale gave us the diameter ratio loss corresponding to each corrosion time. Thus, the estimated rate of ultimate force loss is drawn in function of the fraction of life. The comparison is made with the experimental curve obtained from tensile test on the corroded strands. A good matching appears between the two curves.

As a result, by evaluating the bearing force of wire rope affected by corrosion during its life service, engineers can assess the possibility of maintaining the structure in service and define the time of removal. This way conciliation is ensured between optimization and reliability of the structure. 


\section{REFERENCES}

[1] Calgaro, J.-A., Bernard-Gely, A. (2009). Conception des ponts Démarche de conception, Tech. l’ingénieur Les Routes, Les Ponts Les Joints, c4496.

[2] Brevet, P., Olivie, F., Guilbaud, J.P., Raharinaivo, A. (2004). Microstructure et propriétés mécaniques des aciers pour câbles, Bull. Ddes Lab. Des Ponts Chaussées, pp. 35-48.

[3] Raoof, M., Kraincanic, I. (1998). Determination of wire recovery length in steel cables and its practical applications, Comput. Struct., 68(5), pp. 445-59, DOI: 10.1016/S0045-7949(98)00088-1.

[4] Chaplin, C.R. (1995). Failure mechanisms in wire ropes, Eng. Fail. Anal., 2(1), pp. 45-57, DOI: 10.1016/1350-6307(95)00004-A.

[5] Brevet, P. (2005). Pathologie des haubans et cables fatigue - corrosion, Journée Câbles 2005, Laboratoire Central des Ponts et Chaussées.

[6] Perrin, M., Gaillet, L., Tessier, C., Idrissi, H. (2010). Hydrogen embrittlement of prestressing cables, Corros. Sci., 52(6), pp. 1915-26, DOI: 10.1016/j.corsci.2010.02.041.

[7] Périer, V., Dieng, L., Gaillet, L., Tessier, C., Fouvry, S. (2009). Fretting-fatigue behaviour of bridge engineering cables in a solution of sodium chloride, Wear, 267(1-4), pp. 308-14, DOI: 10.1016/j.wear.2008.12.107.

[8] Zampieri, P., Curtarello, A., Pellegrino, C., Maiorana, E. (2017). Fatigue strength of corroded bolted connection, Frat. Ed Integrità Strutt., 12(43), pp. 90-96, DOI: 10.3221/IGF-ESIS.43.06.

[9] Wang, D., Zhang, D., Zhao, W., Ge, S. (2014). Quantitative analyses of fretting fatigue damages of mine rope wires in different corrosive media, Mater. Sci. Eng. A, 596, pp. 80-88, DOI: 10.1016/j.msea.2013.12.047.

[10] Beltrán, J.F., Williamson, E.B. (2011). Numerical procedure for the analysis of damaged polyester ropes, Eng. Struct., 33(5), pp. 1698-1709, DOI: 10.1016/j.engstruct.2011.02.007.

[11] Beltrán, J.F., De Vico, E. (2015). Assessment of static rope behavior with asymmetric damage distribution, Eng. Struct., 86, pp. 84-98, DOI: 10.1016/j.engstruct.2014.12.026.

[12] Wang, D., Zhang, D., Ge, S. (2012). Effect of displacement amplitude on fretting fatigue behavior of hoisting rope wires in low cycle fatigue, Tribol. Int., 52, pp. 178-89, DOI: 10.1016/j.triboint.2012.04.008.

[13] Torkar, M., Arzenšek, B. (2002). Failure of crane wire rope, Eng. Fail. Anal., 9(2), pp. 227-233, DOI: 10.1016/S1350-6307(00)00047-9.

[14] Elachachi, S.M., Breysse, D., Yotte, S., Cremona, C. (2006). A probabilistic multi-scale time dependent model for corroded structural suspension cables, Probabilistic Eng. Mech., 21(3), pp. 235-45, DOI: $10.1016 / \mathrm{j} \cdot$ probengmech.2005.10.006.

[15] ISO 6892. (1984). Matériaux métalliques - Essai de traction, ,.

[16] ISO 7539-1. (2012). Corrosion of metals and alloys - Stress corrosion testing - Part 1: General guidance on testing procedures.

[17] Wang, S., Zhang, D., Chen, K., Xu, L., Ge, S. (2014). Corrosion fatigue behaviors of steel wires used in coalmine, Mater. Des., 53, pp. 58-64, DOI: 10.1016/j.matdes.2013.06.059.

[18] Meknassi, M., Mouhib, N., Tijani, A., El Ghorba, M. (2015). Experimental study of wires extracted from steel wire rope and exposed to sulfuric acid, IPASJ Int. J. Mech. Eng., 3(11), pp. 47-53.

[19] Tijani, A., Meknassi, M., Chaffoui, H., Elghorba, M. (2017). Combined Effect of Broken Rope Components and Corrosion on Damage Evolution through Its Lifetime, J. Mater. Civ. Eng., 29(7), pp. 04017035, DOI: 10.1061/(ASCE)MT.1943-5533.0001846.

[20] Stewart, M.G., Al-Harthy, A. (2008). Pitting corrosion and structural reliability of corroding RC structures: Experimental data and probabilistic analysis, Reliab. Eng. Syst. Saf., 93(3), pp. 373-382, DOI: $10.1016 /$ j.ress.2006.12.013.

[21] Val, D. V., Melchers, R.E. (1997). Reliability of Deteriorating RC Slab Bridges, J. Struct. Eng., 123(12), pp. 1638-44, DOI: 10.1061/(ASCE)0733-9445(1997)123:12(1638).

[22] Périer, V., Dieng, L., Gaillet, L. (2007). Modélisation de la fatigue de contact dans les câbles corrodés, 18ème Congrès Français de Mécanique.

[23] François, R., Arliguie, G., Escadeillas, G., Francy, O. (1998). Optimisation des structures en béton armé vis-à-vis de la corrosion, Rev. Française Génie Civ., 2(8), pp. 949-968, DOI: 10.1080/12795119.1998.9692221. 